\title{
Mechanistic Investigations of Surface Modification of Carbon Black and Silica by Plasma Polymerisation
}

\author{
T. Mathew $\cdot$ R. N. Datta $\cdot$ W. K. Dierkes $\cdot$ J. W. M. Noordermeer $\cdot$ \\ W. J. van Ooij
}

Received: 24 August 2007/Accepted: 11 January 2008/Published online: 7 February 2008

(C) The Author(s) 2008

\begin{abstract}
Carbon black is widely used as an active filler in the rubber industry to improve the physical properties of rubber. The surface energy of carbon black is high compared to that of various elastomers like styrene-butadiene rubber (SBR), butadiene rubber (BR) and ethylene-propylene-diene rubber (EPDM). The work aims at reducing the surface energy of carbon black by modifying its surface for application especially in rubber blends. The present paper looks into the possibility of using plasma polymerisation of acetylene as a surface modification technique for carbon black in comparison with silica. Thermogravimetric analysis, wetting behaviour with various liquids of known surface tension and time of flight secondary ion mass spectrometry (ToF-SIMS) were used to characterise the carbon black before and after surface modification. The study shows that surface modification of carbon black by plasma polymerisation is difficult in comparison with silica, unless treated for long duration. The mechanistic aspects of the surface modification and the importance of active sites on the carbon black surface for effective modification are discussed in the paper.
\end{abstract}

Keywords Carbon black - Plasma polymerisation - Surface energy · Acetylene · Crystallite edges

\section{Introduction}

Carbon black is widely used as an active filler in the rubber industry to improve the physical properties of rubbers [1]. Dispersion and distribution of carbon black in the rubber matrix are important factors for achieving optimum physical properties. The behaviour of

T. Mathew · R. N. Datta - W. K. Dierkes · J. W. M. Noordermeer $(\square)$

Department of Elastomer Technology and Engineering, Faculty of Engineering Technology,

University of Twente, P.O. Box 217, 7500AE Enschede, The Netherlands

e-mail: J.W.M.Noordermeer@utwente.nl

W. J. van Ooij

Department of Material Science and Engineering, University of Cincinnati, Cincinnati, OH 45221, USA 
carbon black in rubber depends mainly on the particle size, surface area, aggregate structure and size, nature of the surface and its activity. Filler-filler and filler-polymer interaction are important factors involved in the dispersion of the filler and reinforcement of the rubber by the filler. A higher filler-filler interaction is marked by a poor dispersion state. The affinity of carbon black towards different elastomers determines the polymerfiller interaction.

During mixing carbon black with rubber, after incorporation, distributive and dispersive processes control the dispersion quality. After an initial breakdown of the macroscopic filler pellets, the wettability of the filler and its interaction with the rubber play an important role towards achieving a good dispersion state. The wettability of a filler particle by a polymer chain can be quantified in terms of surface energy. The surface energy of a filler in turn depends on the physico-chemical composition of its surface. In order to have a good compatibility, the surface energy difference between the filler and rubber should be low. With a large surface energy difference between filler and rubber, the filler-filler interaction increases, which in turn has a negative influence on the stability of the dispersion state attained during mixing. In the case of carbon black, the surface energy is high compared to that of various elastomers like styrene-butadiene rubber (SBR), butadiene rubber (BR) and ethylene-propylene-diene rubber (EPDM). It is also worth to mention that the surface energy of silica, another filler used in the rubber industry, is even higher than that of carbon black, which corresponds to an even stronger filler-filler interaction than for carbon black [2].

It is possible to tailor the surface properties of a filler. Plasma polymerisation has emerged as a surface modification technique for metals, polymers and powders. The technique involves electric field bombardment of monomer molecules, thereby creating active monomer species, which then react with the surface to form a film over the substrate. As a result, the surface properties of the substrate change dramatically. By suitable selection of monomers, a substrate can either be made hydrophobic or hydrophilic. Plasma polymerisation can be carried out at ambient temperature and does not require any solvents for the process, making it a clean process.

Contrary to the vast amount of information available on the plasma deposition on flat surfaces $[3,4]$, there are only few reports on the deposition on powder substrates. Powders are difficult to handle in plasma treatment, mainly because of aggregation and the large surface area per unit mass of the powder. Inagaki et al. [5] reported surface modification of polyethylene powders using a fluidised bed. Later, van Ooij et al. [6-8] reported surface modification of various powder substrates using different reactors, which included a vertical tubular reactor, a tumbler reactor and a fluidised bed reactor.

The extension of plasma polymerisation as a surface modification technique for fillers like carbon black and silica for application in rubber happened quite recently. Nah et al. [9, 10] reported plasma polymerisation on silica and its effect on rubber properties. Borros and co-workers $[11,12]$ reported modification of various curatives like sulphur and cyclohexylbenzothiazole sulphenamide. Donnet et al. [13] has reported on the plasma treatment of graphitised carbon black using reactive gases. Their study showed that after plasma treatment the graphitised surface appeared to be more like that of regular carbon black than that of graphite. Akovali and Ulkem [14] and Tricas et al. [15, 16] reported the modification of carbon black by plasma polymerisation. The monomers used for the process were styrene, butadiene, and acrylic acid. Their findings led to the conclusion that carbon black was modified successfully, with the coating covering all sites on the surface. Kang and van Ooji [17] also reported on the modification of carbon black by plasma polymerisation and concluded that it is possible to manipulate the surface properties. 
The present work looks into the possibilities of plasma polymerisation as a surface modification technique for carbon black, with the aim of reducing its surface energy, by applying a hydrophobic coating over the surface. The monomer chosen for this purpose is acetylene. The modified filler is characterised by thermogravimetric analysis (TGA), wetting behaviour with various liquids of known surface tension and time of flight secondary ion mass spectrometry (ToF-SIMS). In this paper, we report on the mechanistic aspects of surface modification and on the importance of active sites on the surface of carbon black for an effective surface modification by plasma polymerisation. For reason of comparison some experiments on a silica sample are included.

\section{Experimental}

\section{Materials}

The type of carbon black chosen for the modification process was carbon black N330 in the fluffy state, as supplied by Degussa AG, Germany. The surface area of the N330 carbon black was $83 \mathrm{~m}^{2} / \mathrm{g}$ (BET-nitrogen adsorption surface area). The type of silica used in the comparative experiments was a rubber grade-Hi Sil 233, as obtained from PPG, USA, for which the surface area was $152 \mathrm{~m}^{2} / \mathrm{g}$. The monomer used for plasma polymerisation was acetylene ( $99.6 \%$ purity), as supplied by Matheson tri gas, USA.

\section{Methods}

\section{Plasma Polymerisation}

Plasma polymerisation was carried out in a radio frequency (RF) plasma tumbler reactor at the University of Cincinnati, Ohio, USA [6]. A schematic representation of this reactor is shown in Fig. 1. After introduction of the powder, the chamber was evacuated to a pressure of $10 \mathrm{~Pa}$. Then monomer was injected into the reaction chamber under steady flow conditions, maintaining the monomer pressure inside the chamber at $20 \mathrm{~Pa}$. Subsequently RF power was applied. The frequency was $13.56 \mathrm{MHz}$. The conditions of the process were varied as given in Table 1. The powder samples were mixed inside the chamber with the help of two vanes running in opposite direction on a shaft inside the chamber. This aids in exposing the powder particles to the plasma, in order to obtain uniform modification all over their surface.

\section{Thermogravimetric Analysis}

A Perkin Elmer TGA was used for TGA of the samples. The samples were heated from 50 to $800^{\circ} \mathrm{C}$ at $10^{\circ} \mathrm{C} / \mathrm{min}$ in an air atmosphere. The thermal degradation behaviour of pure plasma polymerised acetylene was first studied. Pure plasma polymerised acetylene starts decomposing at $265^{\circ} \mathrm{C}$ and the decomposition is complete at $600^{\circ} \mathrm{C}$. Based on this, the weight losses for the coated and uncoated carbon blacks were calculated in this region of decomposition of plasma polymerised acetylene. The difference in weight loss between the coated and uncoated samples corresponds to the amount of coating deposited on the surface of the carbon blacks. 


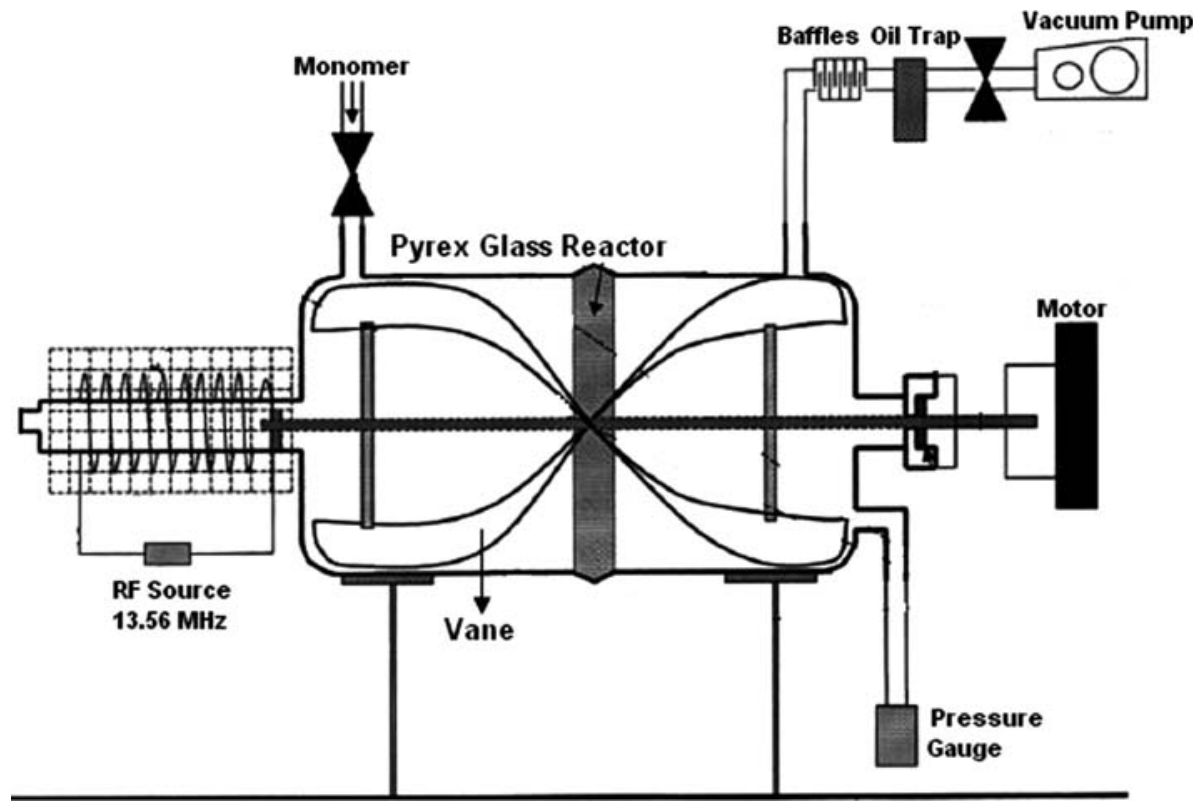

Fig. 1 Schematic representation of the radio frequency (RF) plasma tumbler reactor

Table 1 Experimental conditions employed for the plasma polymerisation

\begin{tabular}{llll}
\hline $\begin{array}{l}\text { Sample } \\
\text { code }\end{array}$ & $\begin{array}{l}\text { RF power } \\
(\mathrm{W})\end{array}$ & $\begin{array}{l}\text { Monomer } \\
\text { concentration } \\
(\mathrm{Pa})\end{array}$ & $\begin{array}{l}\text { Treatment } \\
\text { time }\end{array}$ \\
\hline N330-1 & 30 & 20 & $1 \mathrm{~h}$ \\
N330-2 & 60 & 20 & $1 \mathrm{~h}$ \\
N330-3 & 90 & 20 & $1 \mathrm{~h}$ \\
N330-4 & 90 & 40 & $1 \mathrm{~h}$ \\
N330-5 & 90 & 40 & $4 \mathrm{~h}$ \\
Silica & 90 & 40 & $1 \mathrm{~h}$ \\
Metal plate & 60 & 20 & $15 \mathrm{~min}$ \\
\hline
\end{tabular}

Wetting Behaviour with Liquids of Known Surface Tension

Wetting behaviour of the modified and unmodified powders with liquids of known surface tension was observed in order to semi-quantitatively characterise the degree to which the modification had taken place. For this purpose, $50 \mathrm{ml}$ of liquid was put in a glass beaker and 1-2 $\mathrm{g}$ of sample was added to the liquid. Depending on the surface energy of the powder, it will either sink or float on the liquid. The wetting behaviour gives an idea about the range over which surface energy has been reduced.

Time of Fight Secondary Ion Mass Spectroscopy (ToF-SIMS)

In order to study the surface composition of the coated carbon blacks, ToF-SIMS measurements were carried out. ToF-SIMS is a very sensitive surface analysis technique, which 
especially looks at the uppermost layers of the surface. The measurements were carried out in an Ion-Tof Cameca ToF-SIMS IV machine. The carbon black powder samples were deposited on an indium foil, which was then loaded on to the sample holder. The system vacuum was maintained at between $10^{-7}$ and $10^{-9}$ mbar. Monoisotopic Gallium $\left({ }^{69} \mathrm{Ga}\right)$ ions were used as the primary ion source and the primary ion source energy was $25 \mathrm{kV}$. The ion current was kept in the range $1.5-2.5 \mu \mathrm{A}$. The total integrated ion dose was $\approx 10^{10}$ ions $/ \mathrm{cm}^{2}$.

\section{Results}

The plasma reactor is based on the tumbling of powders in a cylindrical chamber into which an organic monomer is introduced to produce low temperature plasma, which results in the deposition of plasma polymerised film on the powder surface. Powders are treated in the remote plasma zone i.e., away from the most intense glow. In the remote plasma zone there will be more radicals than the electron and ions because of the life time differences. In a pioneering work, characterization of this tumbler reactor has been carried out via the deposition rate measurements of plasma polymer film deposited on silicon wafers under different conditions [18]. Longitudinally, the deposition rate decreases significantly when it moves from the central plasma zone to the remote plasma zone, while remaining constant in the remote plasma zone. With appropriate shielding, the decay in the deposition rate in the longitudinal direction can be effectively reduced and a uniform plasma distribution is achieved within the chamber where powders are treated. Radially, at a particular level, the deposition rate on the shaft is generally higher than that on the chamber wall. However, since during the process, powder particles are mixed by the vanes up and down as well as to and fro, hence the opportunities for each particle to visit at different radial positions are almost the same. Therefore, the radial difference in deposition rate will not appreciably affect the homogeneity of the plasma polymer film on powder surfaces.

The TGA thermogram of plasma polymerised acetylene is shown in Fig. 2a. The decomposition starts at $265^{\circ} \mathrm{C}$ and is complete at $600^{\circ} \mathrm{C}$. The TGA thermograms of the various coated and uncoated carbon black samples are shown in Fig. 2b. The weight loss in the region of decomposition of plasma polymerised acetylene was calculated from the thermograms of the coated and uncoated carbon blacks. The difference in weight loss of the coated and uncoated carbon black samples corresponds to the weight of the plasma polymerised acetylene film deposited on the surface of carbon black. The calculated weight losses of various treated carbon black samples are mentioned in Table 2 . The $1 \mathrm{~h}$ treated samples show only a little amount of deposition. The $4 \mathrm{~h}$ treated carbon black sample shows an increased weight loss, indicating that there is a more than proportional deposition as treatment time is increased.

For a liquid to wet a particular surface, the surface energy of the liquid has to be lower than that of the substrate. The wetting behaviour of carbon black samples in liquids of known surface tension gives an indication about the range over which the surface energy has been reduced. The wetting behaviour of coated and uncoated carbon black samples are summarised in Fig. 3. After the formation of the plasma polymerised acetylene film the surface of carbon black should show characteristics corresponding to the formed acetylene film: a lower surface energy. This also depends on the surface coverage of the film. All $1 \mathrm{~h}$ treated carbon black samples show a slight reduction in surface energy, without differences amongst the separate samples. The $4 \mathrm{~h}$ treated carbon black shows an appreciable reduction in surface energy, which corresponds with the substantial deposition as already evident from the TGA results. 

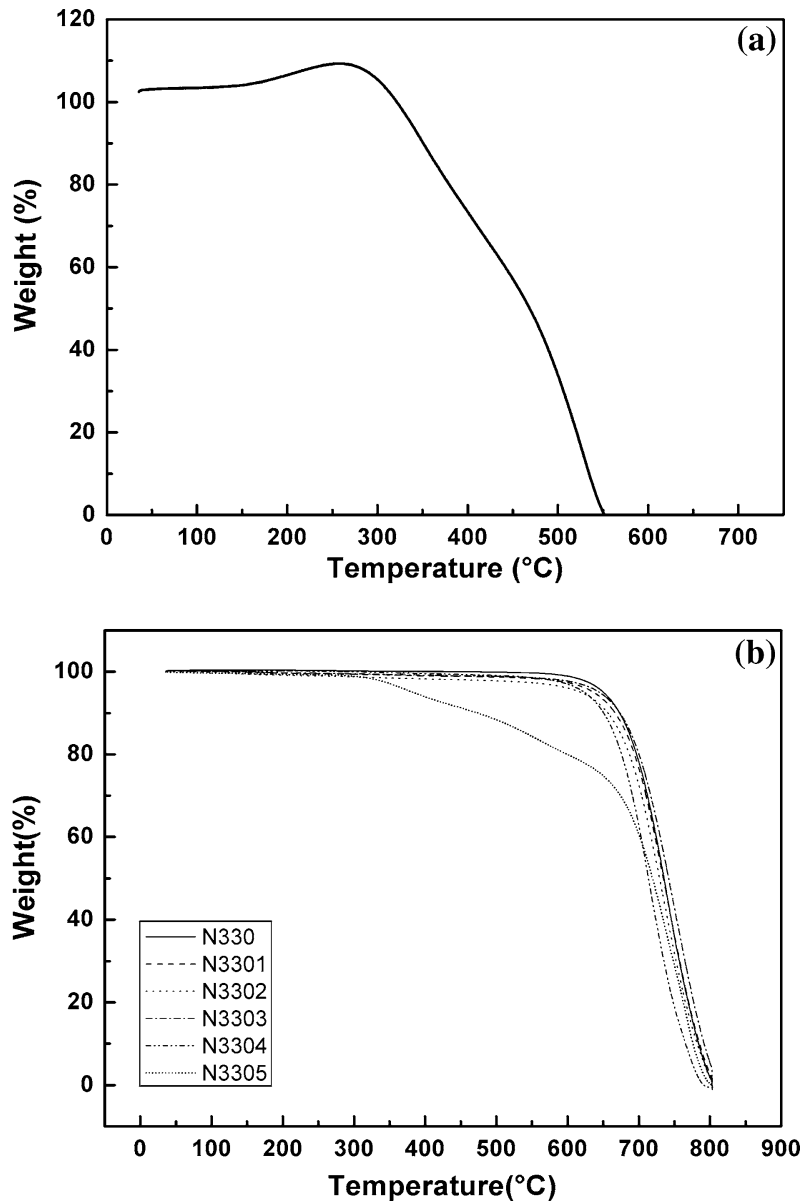

Fig. 2 TGA thermograms of (a) plasma polymerised acetylene and (b) carbon black samples

Table 2 Calculated weight losses for various powder samples
Weight loss $(\%)$

\begin{tabular}{lc}
\hline $\mathrm{N} 330-1$ & 1.02 \\
$\mathrm{~N} 330-2$ & 1.37 \\
$\mathrm{~N} 330-3$ & 0.35 \\
$\mathrm{~N} 330-4$ & 2.32 \\
$\mathrm{~N} 330-5$ & 17.6 \\
Silica & 5.12 \\
\hline
\end{tabular}

Plasma polymerisation of acetylene will result in the formation of a crosslinked hydrocarbon film. In a positive ToF-SIMS spectrum, such a hydrocarbon must show a cluster pattern of mass fragments, especially in the higher mass fraction regions [19]. ToFSIMS spectrum of untreated carbon black is shown in Fig. 4. The SIMS spectrum of untreated carbon black displays some hydrocarbon peaks and signal corresponding to $\mathrm{Na}^{+}$. This is characteristic of a carbon black surface. Detailed studies of carbon black surface 


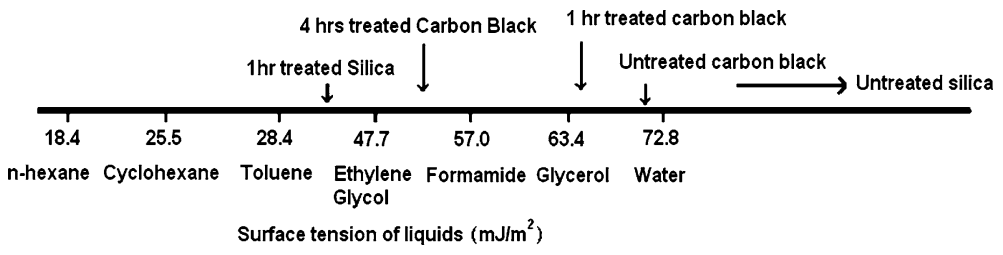

Fig. 3 Schematic representation of wetting behaviour of treated carbon blacks and silica
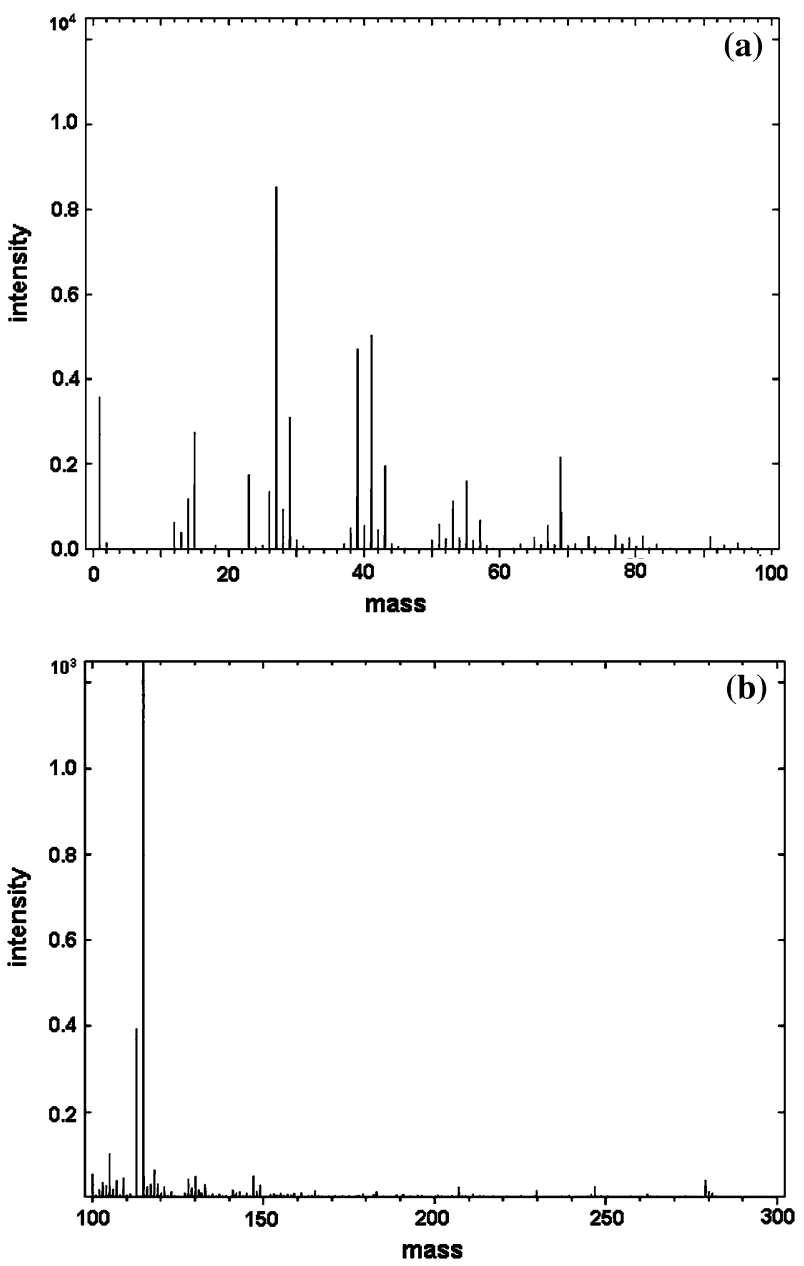

Fig. 4 Positive ToF-SIMS spectrum of representative untreated carbon black. (a) Mass range 0-100 and (b) mass range $100-300$

using ToF-SIMS have been reported earlier by Poleunis et al. [20]. A ToF-SIMS spectrum of a representative $1 \mathrm{~h}$ treated carbon black sample (N330-2) is shown in Fig. 5. For comparative purposes, acetylene was plasma polymerised on to a metal plate under the same conditions as used for carbon black and the ToF-SIMS spectrum of such a film was 

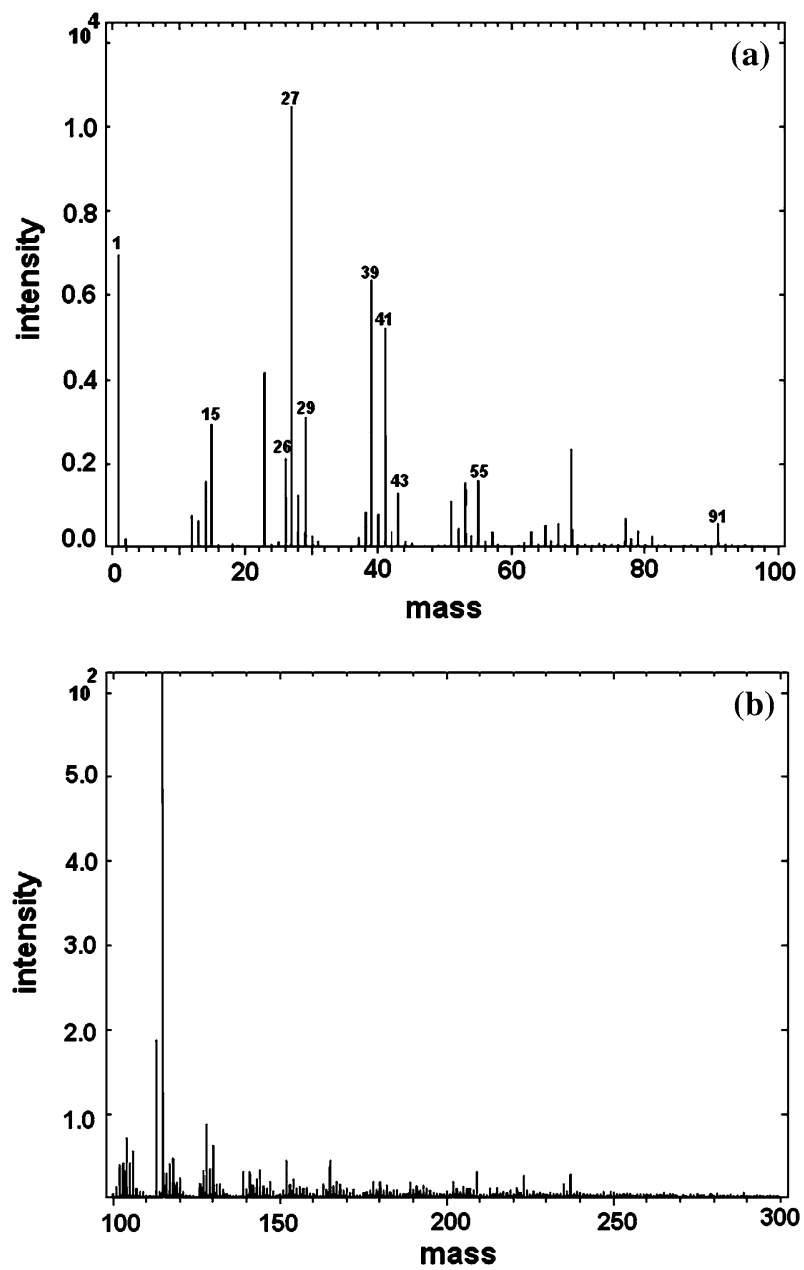

Fig. 5 Positive ToF-SIMS spectrum of representative carbon black treated for $1 \mathrm{~h} \mathrm{(N330-2).} \mathrm{(a)} \mathrm{Mass}$ range $0-100$ and (b) mass range 100-300

also taken (Fig. 6). Peak assignments for some significant peaks are listed in Table 3 [21]. The spectrum obtained for the plasma polymerised acetylene film shows the presence of highly intense peaks corresponding to the hydrocarbon composition. Also in the higher mass fraction regions, the spectrum shows a cluster pattern of mass fragments typical of hydrocarbons, thereby confirming the formation of a neat hydrocarbon film on the surface of the metal plate.

The ToF-SIMS spectrum of the $1 \mathrm{~h}$ treated carbon black shows less intense hydrocarbon peaks and shows only a small extent of cluster pattern in the higher mass fraction regions. This, combined with the lower deposition levels as seen from TGA results and only the slight reduction in surface energy from wetting behaviour, points towards the fact that deposition may have happened only locally without formation of a complete film over the surface.

Plasma polymerisation on powder substrates is usually different from that on a flat surface. Factors like the higher specific surface area of the powder and duration of surface 

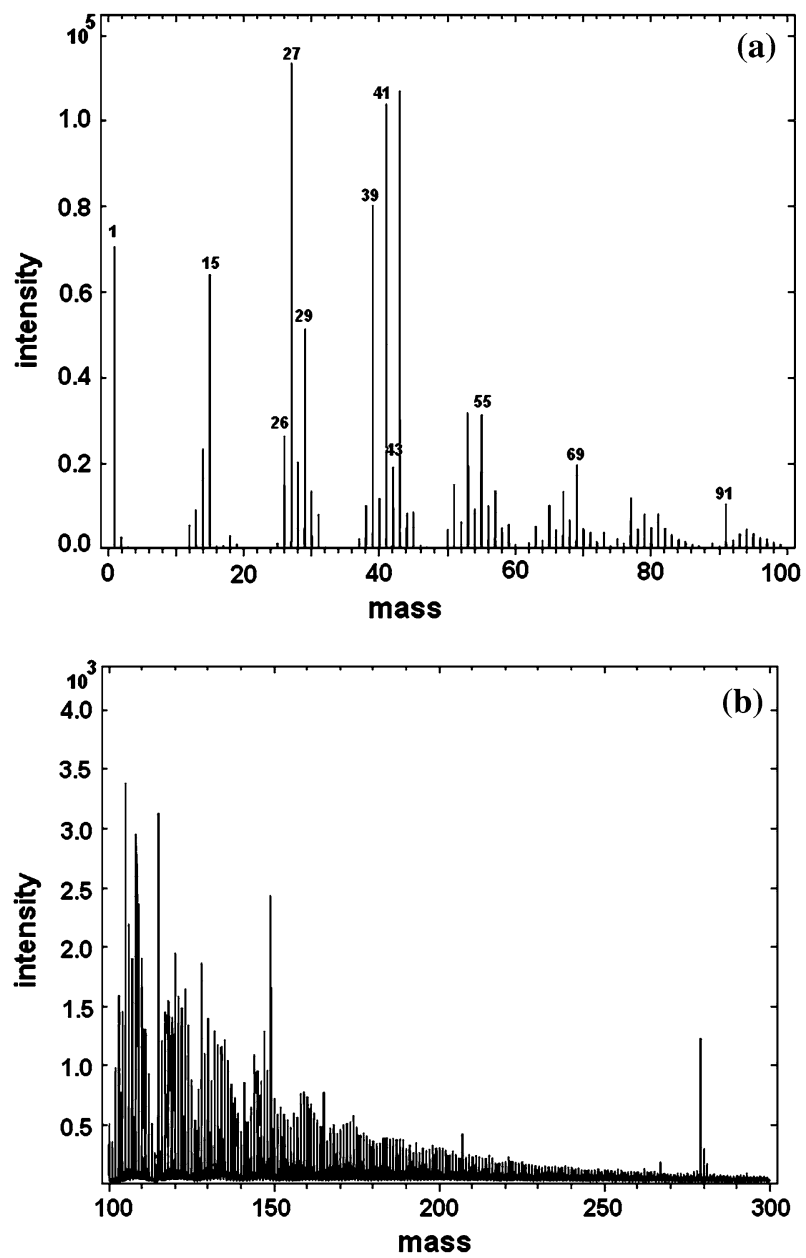

Fig. 6 Positive ToF-SIMS spectrum of plasma polymerised acetylene on a metal plate. (a) Mass range $0-100$ and (b) mass range 100-300

exposure to plasma contribute to this difference. Due to the large surface area, the monomer concentration around the powder surface is much lower compared to that around a flat surface. The growth of the plasma polymer on powder surface is slowed down because the monomer and radicals around the powder surface are depleted and exhausted. Hence the plasma polymerisation on powder substrates proceeds in a monomer-lean region. Therefore, two more experiments were carried out on carbon black at a higher monomer concentration and at longer treatment time. The conditions for the processes are mentioned in Table 1. The ToF-SIMS spectrum of the carbon black treated at a higher monomer concentration is shown in Fig. 7: no significant improvement in the cluster pattern behaviour can be observed. The spectrum of the $4 \mathrm{~h}$ treated carbon black (N330-5) is shown in Fig. 8. It shows a clearer cluster pattern, indeed indicating a better coverage of the plasma polymer on the surface than for the $1 \mathrm{~h}$ treated sample. However, the development of a cluster pattern as seen in Fig. 6 is still in no way achieved. A siloxane contamination in a ToF-SIMS was observed on the carbon black surfaces, especially on the 
Table 3 Ion fragments in positive ToF-SIMS spectra

\begin{tabular}{ll}
\hline Mass & Composition \\
\hline $1^{+}$ & $\mathrm{H}^{+}$ \\
$15^{+}$ & $\mathrm{CH}_{3}^{+}$ \\
$26^{+}$ & $\mathrm{C}_{2} \mathrm{H}_{2}^{+}$ \\
$27^{+}$ & $\mathrm{C}_{2} \mathrm{H}_{3}^{+}$ \\
$29^{+}$ & $\mathrm{C}_{2} \mathrm{H}_{5}^{++}$ \\
$39^{+}$ & $\mathrm{C}_{3} \mathrm{H}_{3}^{+}$ \\
$41^{+}$ & $\mathrm{C}_{3} \mathrm{H}_{5}^{+}$ \\
$43^{+}$ & $\mathrm{C}_{3} \mathrm{H}_{7}^{+}$ \\
$55^{+}$ & $\mathrm{C}_{4} \mathrm{H}_{7}^{+}$ \\
$69^{+}$ & $\mathrm{Ga}^{+}$ \\
$91^{+}$ & $\mathrm{C}_{7} \mathrm{H}_{7}^{+}$ \\
$114^{+}$ & $\mathrm{In}^{+}$ \\
\hline
\end{tabular}

Fig. 7 Positive ToF-SIMS spectrum of carbon black treated for $1 \mathrm{~h}$ at a higher monomer concentration (N330-4). (a) Mass range 0-100 and (b) mass range $100-300$
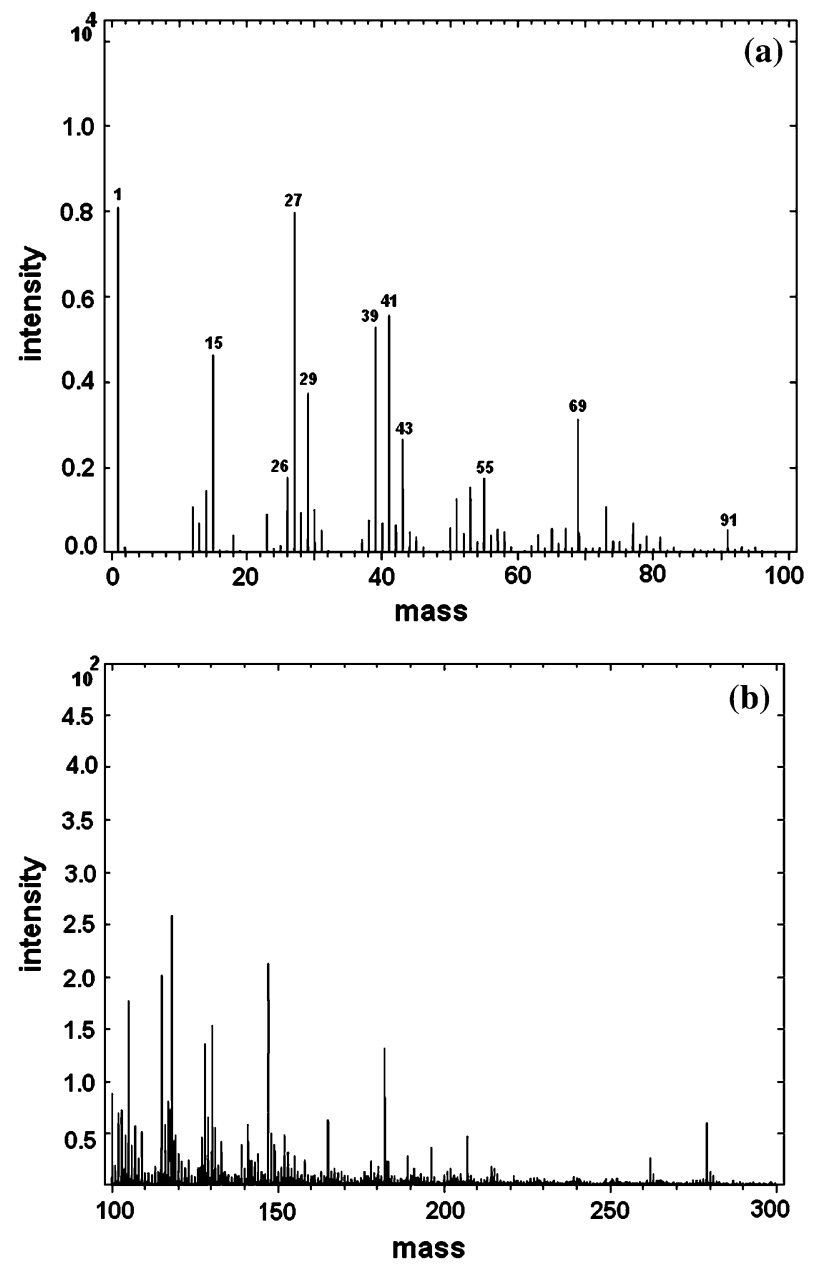
Fig. 8 Positive ToF-SIMS spectrum of carbon black treated for $4 \mathrm{~h}(\mathrm{~N} 330-5)$. (a) Mass range $0-100$ and (b) mass range 100-300
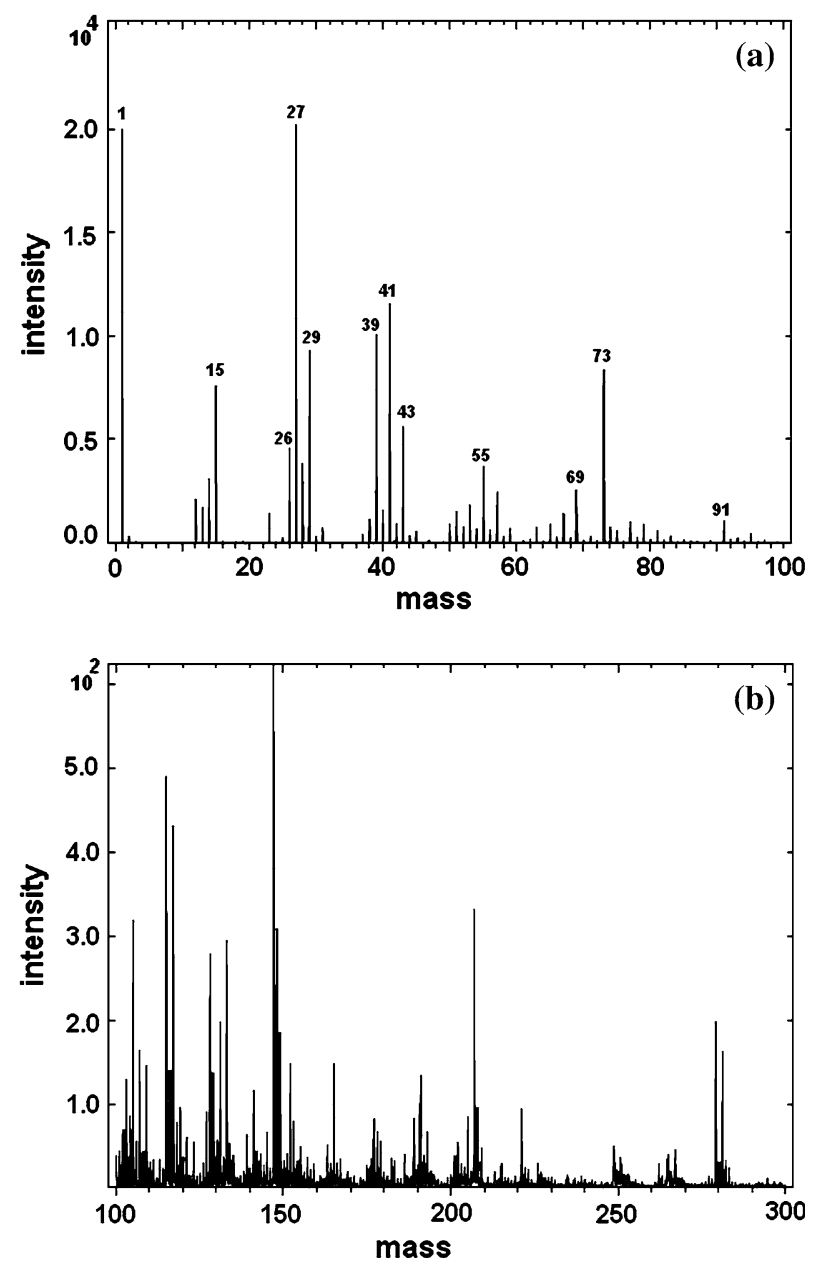

$4 \mathrm{~h}$ treated sample (Fig. 8). Peaks at $73\left(\mathrm{C}_{3} \mathrm{H}_{9} \mathrm{Si}^{+}\right)$and $147\left(\mathrm{C}_{5} \mathrm{H}_{15} \mathrm{OSi}_{2}^{+}\right)$corresponds to the siloxane contamination.

Based on the above observations it is clear that carbon black shows a low tendency for plasma polymer deposition on its surface. In order to quantify this in more detail, a comparative experiment was carried out on the behaviour of silica, another filler commonly used in rubber. The experiment was carried out on silica under the conditions mentioned in Table 1. A $1 \mathrm{~h}$ treatment on silica gave an appreciable reduction in surface energy, as seen in the wetting behaviour of this sample shown in Fig. 3. The ToF-SIMS data also support a strong modification, by the observation of very good cluster pattern, especially in the higher mass fraction regions of the SIMS spectrum (Fig. 9).

\section{Discussion}

It may be concluded that some modification has occurred on the surface of carbon black by deposition of plasma polymerised acetylene, but the extent of modification is very little in 

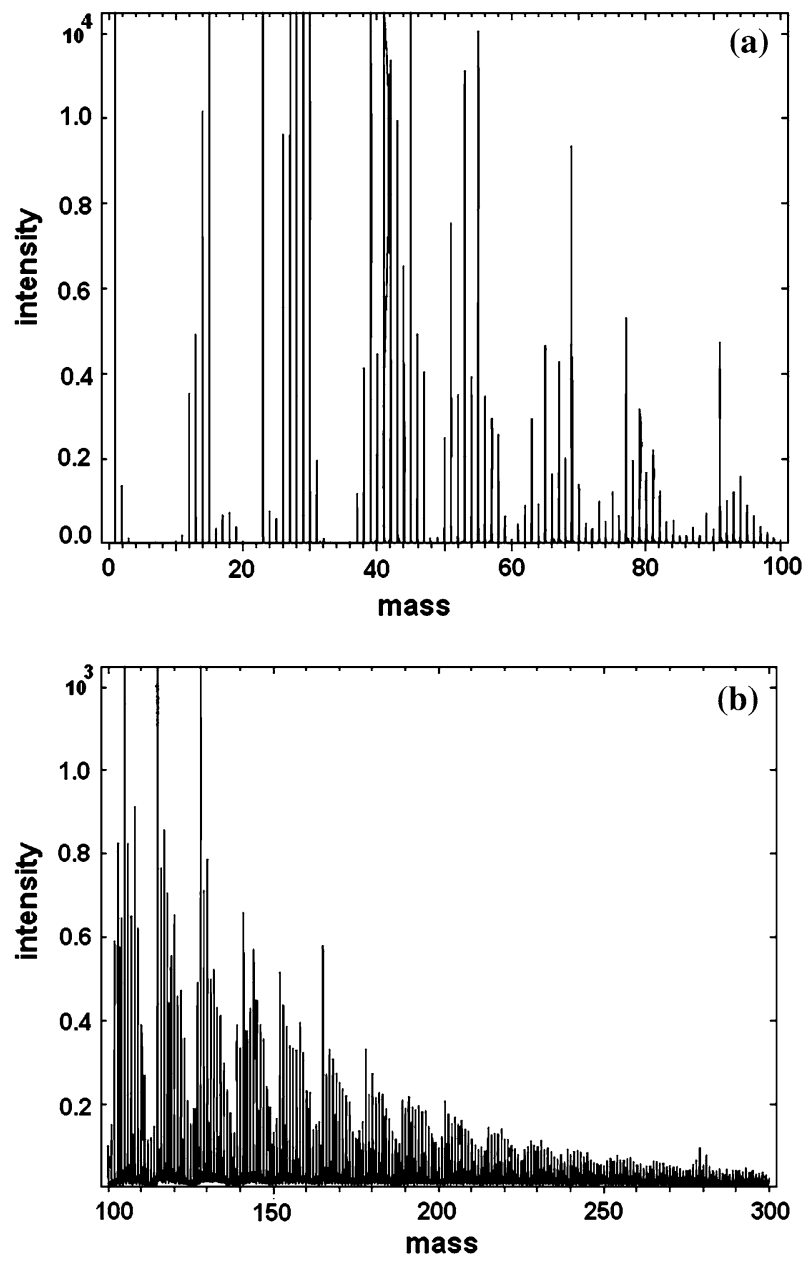

Fig. 9 Positive ToF-SIMS spectrum of silica treated for $1 \mathrm{~h}$. (a) Mass range 0-100 and (b) mass range $100-300$

comparison with the ease with which silica could be modified. The ToF-SIMS results show that silica, which has a surface area of $152 \mathrm{~m}^{2} / \mathrm{g}$, double the amount of experimental carbon black N330 $\left(83 \mathrm{~m}^{2} / \mathrm{g}\right)$, under similar conditions of plasma polymerisation gives much better modification. The wetting behaviour of the silica sample shows an appreciable reduction in surface energy. It clearly shows that a plasma polymerised acetylene film with a good coverage is formed on the surface of the silica.

The surface of carbon black is known to consist of graphitic planes (site I), amorphous carbon (site II), crystallite edges (site III) and slit shaped cavities (site IV) [22] (Fig. 10). The conduction electrons associated with the graphitic structure play an important role in the amount of energy associated with these sites. Recently, Schroeder et al. [22-24] quantified the different energies at these sites on the surface of carbon black by analysing adsorption isotherms of various molecules. According to their analysis, particularly the crystallite edges (III) and slit shaped cavities (1V) on the surface of carbon black are the sites of high concentration of $\pi$-electrons. These sites are most important with respect to 
Fig. 10 Schematic

representation of carbon black

surface (reproduced with

permission from Kautschuk

Gummi Kunststoffe, 2001) [21]

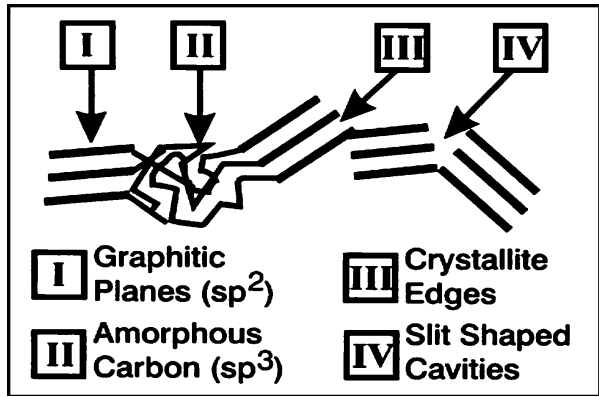

rubber-filler and filler-filler interaction. Furthermore, the surface of carbon black is also covered with functional groups like carboxyl, phenol, lactones and quinonic groups [25]. These are preferably located at the edges of the graphitic basal planes or at the crystallite edges. For furnace carbon blacks, the concentration of these active sites (II-IV) varies between $5 \%$ and $20 \%$ on the surface, and the other $95-80 \%$ contribution is from graphitic planes (site I). Furnace carbon blacks with higher surface area and lower particle size has more fractions of these energetic sites (sites II-IV) (Fig. 10). As the surface area reduces and particles size increases, the fraction of these sites decreases. The carbon black N330 has $\sim 10 \%$ of type II, III and IV sites and the remaining $90 \%$ of the surface consists basically of graphitic planes.

The excitation of gaseous molecules in the plasma generates active species like electrons, protons, excited molecules, ions, etc. The energy required for the formation of a free radical is $3-4 \mathrm{eV}$, whereas the energy required for the formation of ions is $9-13 \mathrm{eV}$. The average electron energy in a low pressure discharge is in the range of $2-5 \mathrm{eV}[26,27]$. This energy is sufficient to break almost all types of bonds. Typical bond energies are given in Table 4. When the filler particles are exposed to the plasma atmosphere, the positive ions colliding on the substrate are capable of creating radical active sites on the surface, to which monomer active species can attach and further grow from there.

Therefore, when carbon black is exposed to plasma, the following processes can happen:

1. $\mathrm{C}-\mathrm{C}$ bond breakage in the graphitic planes. Due to breakage of these $\mathrm{C}-\mathrm{C}$ bonds, radicals are generated on the graphitic planes. However, the graphitic structures are stabilised by resonance. As soon as radicals are generated, they will reform the bond and return to their stable state. In the present case, acetylene was used which generates

Table 4 Bond energy values of typical bonds

\begin{tabular}{lll}
\hline Bond type & $\begin{array}{l}\text { Bond energy } \\
(\mathrm{kJ} / \mathrm{mol})\end{array}$ & $\begin{array}{l}\text { Bond energy } \\
(\mathrm{eV} / \mathrm{mol})\end{array}$ \\
\hline $\mathrm{C}-\mathrm{C}$ & 346 & 3.56 \\
$\mathrm{C}=\mathrm{C}$ & 602 & 6.23 \\
$\mathrm{C} \equiv \mathrm{C}$ & 835 & 8.65 \\
$\mathrm{C}-\mathrm{O}$ & 358 & 3.70 \\
$\mathrm{C}-\mathrm{F}$ & 458 & 4.73 \\
$\mathrm{C}-\mathrm{H}$ & 411 & 4.25 \\
$\mathrm{C}-\mathrm{S}$ & 272 & 2.80 \\
$\mathrm{Si}-\mathrm{O}$ & 452 & 4.68 \\
$\mathrm{Si}-\mathrm{C}$ & 318 & 3.28 \\
\hline
\end{tabular}


radicals of carbon as well. So the system will favour restructuring itself to its original state or to another favourable state by rearrangement. This reduces the chances of attaching a monomer active species on to the graphitic planes.

2. The breakage of $\mathrm{C}-\mathrm{O}$ bonds and other functional groups, located at the crystallite edges. As soon as a $\mathrm{C}-\mathrm{O}$ bond or another functional group located at the crystallite edges is broken, monomer active species can attach on to these sites, which is more favourable.

The thermodynamic feasibility of these processes can also be made clear on basis of the bond energy values (Table 4). The active sites formed on the graphitic basal planes are extremely short lived, so that they revert to their original state before the attachment of monomer active species has happened. Successful attachment of the monomer active species only happens at the sites generated at the crystallite edges, the sites generated by the bond breakage of the functional groups. These sites represent somewhat higher bond energy, and cannot easily stabilise their radical nature by resonance. So it is from these low concentrations of sites on the surface of carbon black that the plasma polymer can grow. That is the reason why so little plasma polymer coverage happens in the first place, to continuously increase with further treatment time.

In the case of silica, on the contrary, the plasma polymer is easily formed on the surface. For silica, densily occurring siloxane and silanol linkages all may be broken, and on to these sites successful attachment of monomer active species may happen. The feasibility of the attachment of monomer species on to the active sites on silica is clear from the bond energy values (Table 4). Once these monomer species are attached they can grow further from these sites. Also, due to the fact that the distribution of functional groups on the surface of silica is very dense, growing chains from neighbouring sites are linked chemically, hence giving a good coverage within a short time, with low energy.

\section{Conclusions}

Plasma polymerisation on carbon black and silica was attempted using acetylene as monomer. TGA, wetting behaviour with different liquids of known surface tension and ToF-SIMS were used as characterisation techniques for the degree of modification. Under the conditions applied, the amount of plasma polymer formed on the surface of carbon black was very little, in comparison with silica, unless treated for very long duration. The thermodynamic feasibility of attachment was explained on the basis of energy values of the various bonds involved. Successful attachment of the monomer active species on the carbon black surface happens only at the crystallite edges, i.e., the very low concentration of sites generated due to bond breakage of functional groups at these locations. Active sites formed on the graphitic planes are extremely short lived, so that they return to their original state because of resonance stabilisation before attachment of monomer active species can take place. In the case of silica, the much higher concentration of functional groups and their random distribution all over the surface aids the easy formation of a plasma polymer film over its surface.

Acknowledgements This is a joint project between University of Twente in the Netherlands and University of Cincinnati in the USA. This research is supported by the Technology Foundation STW, applied science division of NWO, the technology programme of the Ministry of Economic Affairs of the Netherlands under project TPC 6079. Contributions from Hexagon Compounding and Timcal Graphite and Carbon in Belgium are also gratefully acknowledged. 
Open Access This article is distributed under the terms of the Creative Commons Attribution Noncommercial License which permits any noncommercial use, distribution, and reproduction in any medium, provided the original author(s) and source are credited.

\section{References}

1. Donnet JB, Bansal RC, Wang MJ (1993) Carbon black: science and technology, 2nd edn. Marcel Dekker, New York

2. Wolf S, Wang MJ (1992) Rubber Chem Technol 65:329

3. Sabata A, van Ooij WJ, Yasuda HK (1993) Surf Interface Anal 20:845

4. Conners KD, van Ooij WJ, Clarson SJ, Sabata A (1994) J Appl Polym Sci Polym Sym 54:167

5. Inagaki N, Tasaka S, Abe H (1992) J Appl Polym Sci 46:595

6. van Ooij WJ, Zhang N, Guo S (1999) Surface modification of micron size powders by plasma polymerisation process. In: Blitz JP, Little CB (eds) Fundamental and applied aspects of chemically modified surfaces. Royal Society of Chemistry, Cambridge, p 191

7. Shi D, Wang SX, van Ooij WJ, Wang LM, Zhao J, Yu Z (2001) Appl Phys Lett 78(9):1243

8. Chityala A, van Ooij WJ (2000) Surf Eng 16(4):299

9. Mathew G, Huh M-Y, Rhee JM, Lee M-H, Nah C (2004) Polym Adv Technol 15:400

10. Nah C, Huh MY, Rhee JM, Yoon TH (2002) Polym Int 51:510

11. Vidal E, Agulo N, Borros S, van Ooij WJ (2003) Rubber World 21 Aug 2003

12. Vidal E, Borros S, Agullo N, van Ooij WJ (2000) In: Proceedings ACS Rubber Div. Meeting, Cincinnati, paper 91

13. Donnet JB, Wang WD, Vidal A, Wang MJ (1994) Carbon 32:199

14. Akovali G, Ulkem I (1999) Polymer 40:7417

15. Tricas N, Vidal-Escales E, Borros S, Gerspacher M (2003) In: 16th conference of international society of plasma chemistry, Taormina, Italy

16. Tricas N, Borros S, Schuster RH (2004) In: Proceedings of the Kautschuk-Herbst-Kolloquium, Hannover, Germany

17. Kang YC, van Ooij WJ (2006) In: Proceedings ACS rubber div. meeting, Cincinnati, paper 67

18. Zhang N (2000) Masters thesis, University of Cincinnati, USA

19. van Ooij WJ, Brinkhuis RHG (1988) Surf Interface Anal 11:430

20. Poleunis C, vanden Eynde X, Grivei E, Smet H, Probst N, Bertrand P (2000) Surf Interface Anal 30:420

21. Briggs D, Brown A, Vickerman JC (1989) Handbook of static secondary ion mass spectrometry. Wiley, Chichester

22. Schröder A, Klüppel M, Schuster RH, Heidberg J (2001) Kautsch Gummi Kunstst 54:260

23. Schröder A, Klüppel M, Schuster RH, Heidberg J (2002) Carbon 40:207

24. Schroeder A (2000) PhD thesis, Deutsches Institut for Kautschuktechnologie, Hannover, Germany

25. Wang MJ (1998) Rubber Chem Technol 71:520

26. Biederman H (2004) Plasma polymer films. Imperial College Press, London

27. Elwenspoek M, Jansen HV (1998) Silicon micromachining. Cambridge University Press, Cambridge 